On The Record

\title{
Power, competition, and the nature of history
}

\author{
Geerat J. Vermeij (D)
}

\begin{abstract}
Historians have debated whether pathways and events from the past to the present are influenced largely by contingency, the dependence of outcomes on particular prior conditions, or whether there is long-term emergent directional change. Previous arguments for predictability in evolutionary history relied on the high frequency of convergence, but the repeated evolution of widely favored adaptations need not imply long-term directionality. Using evidence from the fossil record and arguments concerning the metabolic evolution of organisms, I show here that power (total energy taken up and expended per unit time) has increased stepwise over time at ecosystem-level and global scales thanks to the ratchetlike, cumulative effects of competition and cooperation and to the disproportionate influence of powerful top competitors and opportunistic species on emergent ecosystem properties and processes. The history of life therefore exhibits emergent directionality at large ecosystem-wide scales toward greater power.
\end{abstract}

Geerat J. Vermeij. Department of Earth and Planetary Sciences, University of California, Davis, Davis, California

95616, U.S.A. E-mail: gjvermeij@ucdavis.edu

Accepted: 28 August 2019

First published online: 14 October 2019

\section{Introduction}

There is a long-standing debate about the nature of history. On one side are those who hold that history is pervaded by contingency, the dependence of outcomes on specific circumstances, pathways, and participants in the past. To many scholars who assign a preeminent role to contingency in evolution, adaptation - the achievement of a close fit between a living organism and its environment - is a local process, constrained by the past and punctuated by major disruptions (Gould 1985, 1996). If long-term historical trends emerge, they are confined to particular lineages, places, and times. According to this view, evolutionary history chiefly entails an increase in variation, ultimately driven by random changes from a particular starting point that retrospectively lies at one end of a distribution of traits (Gould 1996; McShea and Brandon 2010). Natural selection and adaptation occur, but their outcomes are so diverse that in the aggregate, and at the levels of taxonomy and phylogeny, they result in patterns that can be described without reference to them. Taxa, lineages, and clades come and go. The metaphor encapsulating the contingency argument is that, if the "tape of life" were replayed elsewhere, the resulting taxa and clades would differ dramatically from those that actually evolved on Earth (Simpson 1964; Gould 1989; Beatty 2006; Powell 2012; Powell and Mariscal 2015; Losos 2017).

On the other side are those who contend that selective processes leading to adaptation accumulate to impart long-term historical directionality (Conway Morris 2003; Vermeij 2006). Although most modern writers reject notions of a goal-directed force and rightly avoid such words as progress, determinism, and inevitability to describe directionality, proponents of the argument claim that the constraints of prior conditions are overcome by adaptive changes in predictable directions, resulting in the emergence of predictable, broadly beneficial structures and relationships.

No historian would deny the role of contingency in temporal sequences or in the particulars of time and place, nor the demonstrated emergence of long-term trends by the accumulation of chance events when the starting point is at one end of the distribution of characteristics (McShea and Brandon 2010; Schinazi 2019). The debate is therefore not about whether contingency or directionality prevails, 
but whether and how the particular effects of earlier events and conditions are obliterated with time by processes that obey law-like principles.

The principal evidence that has been used in support of a temporally limited role for contingency is the repeatability of evolution, the observation that most adapted states of organisms have evolved multiple times either by convergence from different points of origin or by parallelism, with the same changes occurring in closely related lineages (Conway Morris 2003; Vermeij 2006; Ord and Summers 2015; Losos 2017; Blount et al. 2018). Although the repeated evolution of particular adaptations (particularly those that are beneficial under many circumstances) could be consistent with the thesis of directionality, it is by itself insufficient as either explanation or rationale. The molecular, developmental, and genetic architecture of organisms is ancient and uniform, raising the possibility that similar adaptations in separate lineages might not have completely independent origins (Shubin et al. 2009; Wake et al. 2011; Lane 2015). Although this argument can be countered by pointing out that the mere existence of the basic building blocks does not guarantee the emergence of favored adaptive states or structures (Vermeij 2010), convergence and parallelism might only demonstrate frequently taken pathways followed by some lineages for short durations rather than longterm trends and pervasive directionality. The argument for directionality that follows therefore does not rely on evolutionary repeatability alone, but instead is based on the accumulated selective consequences of underlying competitive and cooperative interactions among metabolizing organisms at the scale of ecosystems and the biosphere as a whole.

Likewise, the claim that early phases of history might be more contingent than later stages (Vermeij 2006; Erwin 2015) could be correct but is not necessary to the argument for the emergence of historical directionality. One argument for early contingency is that all repeated adaptations must have a unique and potentially contingent first appearance. More outcomes are therefore unique in deep time than in more recent periods. A second argument is that phylogenetic and temporal resolution of events and outcomes diminishes back through time, making early historical phases look more contingent than later ones (Vermeij 2006). These two effects could imply greater predictability over time, but neither one necessarily implies directionality. The demonstration of, and explanation for, long-term historical trends must therefore come from arguments and evidence different from those that have been offered previously.

Both sides of this debate focus on participants - lineages and clades in the case of evolution-rather than on the processes to which these participants are subjected. I suggest that this emphasis on actors rather than interactions is misplaced, and that a reorientation toward interactions and their outcomes resolves and essentially eliminates the apparent conflict between a contingent and a directional view of history. In this essay I propose a hypothesis of historical directionality based on power, competition for locally scarce resources, and the ways in which power that is generated by a few participants affects whole ecosystems and ultimately the global biosphere. I argue that (1) universal competition in the broad sense favors winners that use and apply more power than losers; (2) greater access to material and energy sources increases the fit between organism and environment and raises the efficiency of natural selection; (3) powerful agents strengthen interdependencies and positive feedbacks among species and stimulate the establishment and maintenance of stable, productive (that is, powerful) ecosystems that in turn are conducive to the evolution of more vigorous competitors; and (4) the cumulative ratchet effect of these processes and positive feedbacks between organisms and environments is a long-term, stepwise historical trend toward greater system-wide power. This trend thus emerges as a system-wide phenomenon from competition, and should do so wherever life arises as nonidentical entities that compete for and redistribute resources.

McShea and Brandon (2010) propose a third type of historical directionality, which they name the zero-force evolutionary law. According to this view, variation and diversity inevitably accumulate in a system as the sole consequence of mounting error. This is thus 
the null expectation for a system and its parts in the absence of any force - constraint, natural selection, or any other biasing agency-and requires no mechanism other than the frequent introduction and retention of errors. Historical directionality that arises or emerges from constraint, selection, or other forms of bias must therefore be evaluated against a no-force null model by showing that attributes other than or in addition to diversity and variation reveal consistent trends over time. I shall return briefly to this point in the next section, but for now it is sufficient to point out that no natural system, living or otherwise, is free of forces.

\section{The Argument for Directionality}

Organisms need energy to do the work of life, including its signature processes of replication, growth, and maintenance. They must therefore acquire resources, an activity that entails expending power. With more than one organism present, there will be competition for locally scarce resources even when those resources are globally abundant (Vermeij 1987). Competition in its broadest sense is therefore universal at the level of individual organisms or of coherent groups, which consist of separate organisms, but which act as individual-like entities by virtue of coordination among their members (Van Valen 1976). As an interaction among individuals or among coherent groups, competition takes many forms - interference, depletion by rapid exploitation, predation, parasitism, herbivory, defense, mate choice, and cooperation-each with its distinctive attributes and adaptive responses. At first glance, cooperation would seem to be the opposite of competition, but in fact it is a highly effective means for individuals working together to acquire and defend contested resources (Vermeij 1987).

Competition among nonidentical living entities must be evaluated in units of power (energy per unit time), and not energy as Van Valen (1976) maintained. The process is inherently selective. Entities that win competitive encounters gain or use more power (or lose less) than their rivals, as shown experimentally in microcosms by DeLong (2008). By expending more power, winners exert more control over themselves and their environments. Highpower traits associated with competitive winners include a high metabolic rate, as expressed in vertebrate and insect endothermy and in plant photosynthetic capacity. Other traits include active osmoregulation within the body, high mobility (rapid movement over long distances), aggression toward others, elaborate courting and mating displays and structures, active internal transport of materials throughout the body, rapid growth, large allocation of resources to offspring, large body size, and social organization. Losers during competitive encounters may die, as is usual in cases of predation, but they very often survive (Vermeij 1982). Those that do survive have less power, thrive in places where less energy is available, and are more passive in locomotion and physiology than winners. On evolutionary timescales, lineages of losers often lose power and become restricted and specialized to refuges where the threat from competitors is low. The evolutionary process of escalation between enemies and their victims ensures, however, that many other lineages of losers will gain power over the generations as they adapt to co-occurring, increasingly powerful enemies (Vermeij 1987, 2004, 2013a). Power therefore spreads through an ecosystem.

My conception of competition and power differs from Van Valen's (1976) formulation of ideas about energy and evolution. Van Valen (1976) considered what he called "expansive energy" to be the energy equivalence of resources available for producing viable offspring. This concept resembles the ecological concept of fitness favored by Brown et al. (1993), defined as reproductive power, the rate of conversion of energy to offspring by individual organisms. Van Valen (1976) extended the concept of expansive energy to lineages and clades but evidently not to ecosystems. In passing I point out that, as acknowledged by Van Valen (1976) but mainly ignored by him and others (e.g., Chaisson 2001), power is a better measure by which to evaluate competition and other biological processes than is energy, because these processes always involve time as well as energy. Resources are still best expressed in units of energy. 
Note that "winning" refers to access to locally scarce resources by individuals or coherent groups and not to the fate of lineages. Shortterm competitive advantages often conflict with long-term survival of lineages (Van Valen 1975; Van Valkenburgh et al. 2004); and mate selection favoring extravagant displays, coercive behavior, or elaborate but aesthetic structures can interfere with individual fitness and with the persistence of species (Prum 2017), but these expensive processes and outcomes work for winners in the short term regardless of long-term consequences. In any case, reduced power among losers does not mean long-term vulnerability of lineages. Note further that complex societies and evolved mutualisms act as powerful entities even when per capita power is low.

Winners and surviving losers achieve a sufficient (but not necessarily an optimal) fit with their environment. By the word "environment" I mean both the physical and chemical properties of the medium in which individuals live and the biological conditions - food, competitors, predators, and potential mates - with which the individuals interact. The good fit between organism and environment arises both from a genetic or learned response and from active choice and environmental modification. Adaptation, including mate choice, is thus fundamentally a feedback between an organism and its surroundings, not simply a gene-based response to changing conditions (Vermeij 2013a; Oudman and Piersma 2018). Active participation is most obvious in animals with welldeveloped capacities to sense, move, and learn, often leading to goal-directed activity (Gould and Gould 2007; Turner 2007; Corning 2014; McShea 2016b; Levis and Pfennig 2019). Even sedentary fungi with exploratory hyphae and land plants with water-seeking roots and lightseeking aboveground parts grow in preferred directions, and many benefit from mobile animals that disperse their spores and seeds or pollinate their flowers. Importantly, behavior influences the type of natural and sexual selection and improves the fit between organism and environment (Oudman and Piersma 2018). And this involves power. The greater an individual's or coherent group's power, the greater is the potential for a better fit.
The ability to influence and move toward favorable circumstances also increases the efficiency of gene-based natural selection by reducing the role of nonselective chance. If an organism happens to land in an environment poorly suited to its adaptations, and if it cannot modify or leave those conditions, its adaptations cannot be inherited. Greater precision and consistency of the correspondence between adaptive traits and the environment can be achieved if the organism has greater power to change its circumstances, thus making natural selection a more efficient means for maintaining and improving adaptive states. Mulcahy (1979) was one of the first to recognize this point by noting that pollination by animals leads to more efficient natural selection among fertilized embryos than in the case of pollination by wind or water, where pollen often lands in unsuitable places. Sensation, movement, and learning emerged very early in the history of life, with both prokaryotic domains (Archaea and Bacteria) having evolved these capacities, likely by no later than the Archean. Mechanisms for movement in preferred directions have been described in bacteria (Harshey et al. 2003; Polin et al. 2009; Stocker and Durham 2009; Gibiansky et al. 2010; Seymour and Raina 2018) and Archaea (Albers and Jarrell 2015), implying that feedbacks among locomotion, environment, and heritability by genes and culture have existed from close to the origin of life. With the evolution of eukaryotes and later of animals, the scale, speed, and distance of sensation and movement increased as body size increased (Martens et al. 2015), ultimately leading to the evolution of neuromuscular systems and brains (see Jékely and Arendt 2006; Brunet and Arendt 2016). In short, with greater power of competitive winners comes potentially greater precision of the fit between organism and environment, more efficient natural selection, and a larger spatial scale at which organisms interact and adapt.

These same principles apply to mate choice and sexual selection-evolutionarily derived phenomena associated with internal fertilization. Prum (2017) and others regard these two kinds of selection as entirely separate because they conflict with each other. Greater power 
gives organisms engaged in sexual selection more choice and a greater capacity to emphasize expensive, sexually attractive traits; and although these extravagances often conflict with survival-related traits, there are many compromises among traits affected by survivalrelated selection as well.

These feedbacks between organism and environment have intensified as competitive winners successively achieved greater power over time. This was made possible by two intersecting circumstances. First, historical limits on power had to be overcome by rare high-power metabolic and organizational innovations, such as the evolution of the eukaryotic cell with its vastly larger genomes as compared with that of prokaryotes (Lane and Martin 2010), the evolution of endothermy in many vertebrate lineages (Lovegrove 2017) and insects (Heinrich 1993), and metabolic and vascular innovations in land plants (Boyce and Leslie 2012; Brodribb et al. 2013), among many others (see also Vermeij 2017). Second, such high-power innovations succeed only when the ecosystems in which they arise can provide sufficiently predictable, accessible, and abundant resources to sustain a population in which the innovation arises. This involves the evolved or unintended collaboration of other organisms in the ecosystem (Leigh and Vermeij 2002). Competitive winners stimulate this ecosystem-wide capacity through positive feedbacks between enabling factors (resources and the conditions making them available) and selective agents (competitors in the broad sense) (Vermeij 2013a). For example, herbivores often stimulate productivity of their plant foods (e.g., Doughty 2017), sharks promote reef nutrition (Williams et al. 2018), burrowing bivalves increase oxygenation and sediment productivity (Camillini et al. 2019), and cod predation stimulates production in smaller fish prey (Van Leeuwen et al. 2008), among many others. Nutrient recycling by decomposers, detritivores, herbivores, and predators stabilizes and enhances the availability of nutrients, and is thus a collective property of ecosystems (Vermeij 2019) that both enables and is stimulated by increasingly powerful competitors.

Historical directionality toward greater power thus emerges at the ecosystem and global scales from the ratchet-like, cumulative effects of positive feedbacks and interdependencies, led by rare power-enhancing innovations in particular clades of competitors. It should be pervasive: competition is universal, power is favored among winners to the extent permitted by the system, winners stimulate conditions that favor still more power, and evolutionary escalation involving enemies and victims allows power to spread through the system. Details of when power-enhancing innovations arise, which lineages become winners, and where enabling factors are most conducive cannot be predicted and therefore remain in the realm of contingency. The system as a whole, however, is characterized by emergent directionality toward greater power over time as long as positive feedbacks prevail over negative ones.

The mechanism proposed here should operate wherever energy-demanding, nonidentical entities compete and adapt. The rate at which ecosystem-wide power increases will depend on circumstances including the size of the system, the strength of the feedbacks, and the intensity and frequency of power-reducing disruptions.

Por (1994) suggested that the biosphere has relentlessly expanded, a trend he attributed largely to consumption and predation by animals. It is unclear what Por meant by expansion, although it likely involves the establishment of active organisms in regions where such life was previously absent. Predation and activity are obviously important for generating and perhaps accelerating the trend toward increasing power, but this trend should have existed long before the advent of predation and the rise of animals in the late Neoproterozoic. I therefore prefer the more inclusive mechanism of competition, of which predation is a special and important case.

Although the mechanism for directionality proposed here is competition, an argument could be made that the increase in power results from an increase in variance without the intervention of natural selection (McShea and Brandon 2010). All historical trends begin at the low-power end of the distribution of performance (Knoll and Bambach 2000), implying that any step (at least at the beginning of the evolutionary process) must represent an 
increase in maximum power, even if competition and natural selection were not involved. Such scenarios (see also Gould 1996; McShea 1996) are plausible in principle, but competition and adaptation are universal in the living world, so that excluding them as agencies of and responses to change would in my view leave an infinitesimally small domain in which null models apply.

\section{Evidence for Directionality at the Scale of Lineages}

A necessary part of the argument for directionality at the ecosystem scale is that power increased over time among organisms that fulfill particular functions in ecosystems, such as primary producers, suspension feeders, sediment burrowers, swimmers, herbivores, and predators. This increase should be evident at the level of individual organisms, cohesive groups, and evolve mutualisms, expressed either as evolution within lineages or more commonly as replacement of successive independent lineages. Greater power at these levels is indicated by higher metabolic rates (per capita uptake and application of energy and material resources per unit time), which in turn are associated with higher locomotor performance, greater control of internal physiological conditions, faster growth, larger body or group size, and active as compared with passive feeding, defense, and mate choice.

Evidence from the fossil record (summarized in Table 1) is consistent with these expectations. For example, maximum body size within particular guilds-land plants, predators, herbivores, and suspension feeders - rose through time, with the exception of land animals, which reached a peak during the late Mesozoic. In this case, gigantic individuals were replaced by social groups that acted as large individuals. The relatively small individuals in these social species have higher per capita metabolic rates than their earlier counterparts (Vermeij 2016). Over the entire course of the history of life, maximum body size increased by 18 orders of magnitude (Payne et al. 2009; Smith et al. 2016), reflecting an increase in per capita metabolic rates by a factor of $10^{14}$ (DeLong et al. 2010). Most of these increases occurred in two steps, corresponding to the appearance of eukaryotes in the late Paleoproterozoic or early Mesoproterozoic and of animals in the late Neoproterozoic (Payne et al. 2009, 2011). These two steps reveal an increase in body volume from $3.4 \times 10^{-6} \mathrm{~mm}^{3}$ at $3.4 \mathrm{Ga}$ to $10^{2} \mathrm{~mm}^{3}$ at $1.7 \mathrm{Ma}$, and from $10^{2} \mathrm{~mm}^{3}$ to $10^{10} \mathrm{~mm}^{3}$ from $1.7 \mathrm{Ga}$ to $540 \mathrm{Ma}$ (Smith et al. 2016). The subsequent Phanerozoic rise in maximum volume by two orders of magnitude to $10^{12} \mathrm{~mm}^{3}$ (Smith et al. 2016) indicates a much greater absolute rise in per capita power, implying an accelerating rise in individual power over time. Among bottom-dwelling marine invertebrates, mean and maximum body volume increased by factors of 150 and $10^{5}$, respectively, from the Cambrian to the Recent (Heim et al. 2015). Although some large animals are relatively passive - the gentle-giant syndrome - most are very active, implying that large per capita and group size depend on resource-rich environments and

TABLE 1. Long-term trends toward increasing power at the scale of successive lineages.

\begin{tabular}{ll}
\hline \hline Trend & References \\
\hline $\begin{array}{l}\text { Increases in maximum body size } \\
\text { Increases in photosynthetic capacity in: }\end{array}$ & Smith et al. 2016; Vermeij 2016 \\
Land plants & Boyce et al. 2009 \\
$\begin{array}{l}\text { Phytoplankton } \\
\text { Seaweeds }\end{array}$ & Knoll and Follows 2016 \\
Increases in: & Vermeij 2017 \\
Passive skeletal defense & Vermeij et al. 1981; Vermeij 1987, 2004 \\
Locomotor speed and distance traveled & Vermeij 2004; Bush et al. 2016 \\
Food-intake rate & Bambach 1993; Allmon and Martin 2014 \\
Control of internal thermal, osmotic conditions & Turner 2007; Vermeij 2017 \\
Control of stomatal opening/closing in land plants & Brodribb and McAdam 2011; McAdam and Brodribb 2012 \\
Swimming speed in marine animals & Whalen and Briggs 2017 \\
Internal body temperatures & Lovegrove 2017; Vermeij 2017 \\
\hline
\end{tabular}


high metabolic rates (Vermeij 2016; Ferrón 2017; Ferrón et al. 2018).

Increases in photosynthetic capacity occurred stepwise with the evolution of photosynthetic Cyanobacteria followed by the Cryogenian rise of eukaryotic algae between 659 and $645 \mathrm{Ma}$ (Brocks et al. 2017) and the Mesozoic replacement of phytoplankton with greenalgal plastids by those with red-algal plastids (Knoll and Follows 2016). On land, too, there was a stepwise increase in maximum photosynthetic capacity. Multicellular land plants without roots or leaves persisted from the late Cambrian or Early Ordovician to the Early Devonian, when roots and leaves evolved (Hetherington and Dolan 2018), enabling plants to tap more mineral resources from the soil, increase weathering rates, and grow into tree-sized plants. With the evolution of angiosperms (especially eudicots and grasses) beginning about $100 \mathrm{Ma}$ during the Cretaceous, maximum photosynthetic rate increased by fourfold or more (Boyce et al. 2009; Boyce and Leslie 2012; Boyce and Zwieniecki 2019).

Most increases in per capita performance levels over time - all inferred from comparative functional morphology of fossils - reflect higher metabolic rates and larger power budgets. This is perhaps most obvious in the nearly complete replacement of relatively passive shell-bearing cephalopods by more active lineages, in which the shell has become internal or has been lost entirely, beginning in the Early Devonian and essentially complete after the Cretaceous. In land plants, lineages with expensive constitutive chemical defenses were largely replaced by plants (mainly angiosperms) in which defenses are more labile and produced on demand (Robinson 1990). Even increases in the expression of traits associated with passive defense, as seen in bottom-dwelling shell-bearing mollusks, encrusting calcareous coralline algae, and the seed-bearing cones of conifers (Vermeij et al. 1981; Steneck 1983; Vermeij 1987, 2004; Leslie 2011a, b) likely occurred as power budgets rose. Elsewhere I argued, for example, that shell defenses in mollusks evolved as the shell-secreting mantle and body musculature increasingly influenced the directions and rates of shell growth, made possible by greater forces exerted by the animal itself and demonstrating ever greater departures from shells growing under conditions in which forces are minimal (Vermeij 2002). Photosymbioses, which are associated with elevated metabolic activity, have greatly expanded the sizes and skeletal defenses in corals and bivalves (see Vermeij 2013b).

It is important to emphasize that these trends are evident at the extreme of distributions of traits and that they are not necessarily expressed as changes in the mean. Many lineages - probably a large majority, in facthave over their history experienced declines in power after they reached a peak in competitive status, because other lineages eclipsed them in that role. Expressing trends as changes in the mean of a distribution is biologically problematic, because measures of central tendency hide crucial heterogeneity not just in trait values but in ecological roles, including competitive status and power. In any case, I am unaware of any long-term trend toward reduced power among competitive winners in successive lineages of vigorous competitors.

These increases in power at the individual and coherent-group level have been stepwise and global, but they are most pronounced in warm, productive environments and on land, settings where activity and metabolism are least constrained by temperature and by the surrounding medium (Vermeij 2017). The evolution of the human species, which thanks to technology and the exploitation of novel energy sources is the most powerful species (as measured by per capita and collective energy demand) yet to have evolved in the history of life, is consistent with these trends.

In addition, a larger per capita power budget also accommodates a genetic and developmental organization that allows a larger number of functions within the body to be carried out effectively and simultaneously. Such organization entails compartmentalizationmore semiautonomous genetic-developmental modules (Vermeij 2015) - as well as division of labor among parts (Bonner 1952) and high structural hierarchical complexity (McShea 2016a) together with an enhanced capacity for nongenetic (behavioral and immunological) responses to immediate challenges. Wellregulated and evolutionarily well-tested body 
plans may have closed off entirely new configurations (Gould 1989, 1996), but they facilitate the origin and evolution of novel parts and functions (Erwin et al. 2011; Wagner 2014; Erwin 2015). With a larger number of modules and gene networks, power-enhancing novelties can arise without compromising the integrity of the body as a whole (Vermeij 2015).

Innovations that enhance power in individuals represent rare genetic or physiological breakthroughs (Wagner 2014; Lane 2015), implying that long-term increases in power at the high end of the distribution are stepwise and cumulative. Analyses of 23 major power-enhancing innovations of the last 400 Myr indicate that, although they are infrequent, each evolved independently in more than one lineage, and all evolved at times well before or well after mass-extinction events (Vermeij 2017). Lineages in which these innovations evolved were likely competitive opportunists rather than more permanent dominants, able to take advantage of briefly favorable access to availability of resources. They rose to prominence as longerlived competitors following disruptions that selectively eliminated powerful incumbents and that favored high activity in ecosystems in which energy and material resources were plentiful and collectively well regulated.

Stepwise increases in power during the Phanerozoic are particularly evident during the late Ediacaran to early Cambrian, the late Cambrian to Ordovician, the middle Silurian to Devonian, the latest Carboniferous to early Permian, the Late Triassic and Early Jurassic, and the last 100 Myr spanning the Late Cretaceous to the present, culminating in the late Pleistocene origin and Holocene hegemony of modern Homo sapiens (Vermeij 1987, 2004, 2008, 2011a; Peters and Gaines 2012; Erwin 2015).

Maximum body size of both plants and animals has risen over the Phanerozoic to the Recent in the ocean and to the Late Cretaceous on land (Vermeij 2016). The decrease in maximum animal size on land after the Cretaceous could have been compensated by the emergence of coherent social organization in both insects and vertebrates (Vermeij 2017), implying that effective size has come to be expressed at the level of organized groups rather than at the level of individual bodies.
Although the mechanism for these trends proposed here is competition, wherein the winners generate the trends, an argument could be made that the increase in power results from a passive increase in variance without the intervention of natural selection. All the trends begin at the low-power end of the distribution of performance levels (Knoll and Bambach 2000), implying that any step (especially at the beginning of the evolutionary process) must represent an increase in maximum power, even if competition and natural selection were not involved. Such a null model (McShea and Brandon 2010) is plausible in principle, but competition and natural selection leading to adaptation are universal processes in the living world, so excluding them as agencies of change would in my view leave an infinitesimally small domain in which the null model is sufficient. I argue later that the long-term sustenance of greater power is made possible by the disproportionate effect of powerful entities on the whole ecosystem and biosphere.

Increases in maximum power affect a small minority of evolutionary lineages. Most existing lineages follow trajectories at or toward the low-power tail of trait distributions (McShea 1998). Trends toward high power are nonetheless important, because they generate increases in power at the more inclusive scale of ecosystems, or economies, and of the biosphere as a whole. They do so by pushing or restricting less powerful species to parts of the system where energy and material resources are less available or accessible, circumstances under which refugial clades are themselves subject to competition and natural selection favoring higher power in some lineages. Individual-level and group-level trends toward more power therefore percolate through the system in a ratchet-like fashion.

\section{Directionality at the Ecosystem and Global Scale}

At the scale of ecosystems, power is expressed as primary productivity, the rate at which primary producers make fixed carbon available to the system as a whole. Evidence summarized for marine ecosystems by Allmon and Martin (2014) shows that primary productivity has 
generally risen over Phanerozoic time. The largest increases were probably on the seafloor nearshore, where large algae and seagrasses markedly boosted primary productivity during and after the Cretaceous. Compelling arguments from plant physiology demonstrate an increase in primary productivity on land as well, particularly during and after the Cretaceous with the rise of angiosperms (Boyce and Zwieniecki 2019). Lenton et al. (2016) estimate that productivity before the advent of vascular plants was about one-third the present average. With the evolution of deep roots in the Devonian, soil concentrations of carbon dioxide and the rate of weathering (as indicated by solute concentrations) more than doubled, with an additional $7 \%$ to $55 \%$ increase in the late Mesozoic (Ibarra et al. 2019).

Measures of primary productivity over time are difficult to estimate and depend on multiple assumptions. According to Canfield et al. (2006), early Archean primary productivity was at least 14 times lower than present-day marine productivity. For the most common form of anaerobic production at that time (hydrogen-based metabolism), productivity would have been 1000 times lower. Estimates by Ward et al. (2019) place anaerobic Archean primary productivity at less than one-thousandth of modern aerobic values. Crockford et al. (2018) estimate that mid-Mesoproterozoic $(1.4 \mathrm{Ga})$ marine productivity was about $6 \%$ that of the present day. That percentage would be halved if present-day productivity on land, which is about equal to that in the oceans, were added to the modern rate of production. As Boyce and Zwieniecki (2019) argue, modern land-plant productivity was not achieved until the Late Cretaceous. Even as late as the Carboniferous, primary productivity was still very low (Boyce and Zwieniecki 2019).

A significant problem with all these estimates is that they are derived from carbon-isotopic values for organic carbon buried in sediments. In modern ecosystems, very high primary productivity is achieved by rapid and almost complete recycling of carbon and nutrients within the aerobic biosphere. Because the carbon is not buried in geological reservoirs, this activity would be invisible in the fossil record. If the efficiency of recycling has risen over geological time, as I argue elsewhere (Vermeij 2019), the increase in primary productivity over time is likely to have been far greater than currently available estimates indicate.

The temporal increase in ecosystem power is indicated by trends in processes in addition to primary production (Table 2). Bioturbationsediment disturbance by organisms - increases production within and above sediments and has increased stepwise from its earliest occurrence in the latest Ediacaran to the present (Thayer 1983). According to Thayer (1983), there was a 10 -fold increase in the rate of sediment reworking at shelf depth during the Mesozoic. With the advent of extensive bioturbation by fishes and mammals (sirenians and some bottom-feeding cetaceans) during the Cenozoic, the post-Cretaceous marine

TABLE 2. Phenomena indicating increased ecosystem-wide and global power.

\begin{tabular}{|c|c|}
\hline Trait & References \\
\hline \multicolumn{2}{|l|}{ Increases in: } \\
\hline Primary productivity & $\begin{array}{l}\text { Boyce and Lee 2010; Allmon and Martin 2014; Knoll and } \\
\text { Follows 2016; Boyce and Zwieniecki } 2019\end{array}$ \\
\hline Bioturbation in marine sediments & Thayer 1983; Tarhan 2018 \\
\hline Bioturbation in terrestrial soils & Genise et al. 2016 \\
\hline $\begin{array}{l}\text { Vertical and horizontal transport of nutrients in } \\
\text { water by animals and plankton }\end{array}$ & Butterfield 2018 \\
\hline Thickness of shell beds & Kidwell and Brenchley 1996 \\
\hline Biological control over water cycle & Boyce and Lee 2010 \\
\hline Biological control over calcium cycle & Ridgwell and Zeebe 2005 \\
\hline Biological control over silicon cycle & Kidder and Erwin 2001 \\
\hline Herbivory in the sea & Vermeij and Lindberg 2000 \\
\hline Herbivory on land & Labandeira 2006 \\
\hline Predation & Vermeij 1987, 2004 \\
\hline Number of energy sources & Judson 2017 \\
\hline
\end{tabular}


world likely witnessed additional large increases in bioturbation. Kidwell and Brenchley (1996) showed that the thickness of shell beds, reflecting secondary productivity by animals with mineralized skeletons, rose sharply from the advent of mineralized skeletons in the latest Ediacaran to the present. During the early Paleozoic (Ordovician and Silurian), $87 \%$ of shell beds were less than $20 \mathrm{~cm}$ thick, and maximum bed thickness was about $65 \mathrm{~cm}$. For the Jurassic and Neogene, beds less than $20 \mathrm{~cm}$ thick represented $64 \%$ and $33 \%$ of measured shell beds, and maximum shell-bed thickness rose from $2 \mathrm{~m}$ in the Jurassic to $6 \mathrm{~m}$ in the present day (Kidwell and Brenchley 1996). Additional evidence consistent with a rise of primary and secondary productivity is provided by the intensification at the ecosystem and global levels of herbivory, nutrient movements due to increasingly fast-swimming and long-distance movement of animals and vertical and horizontal movement by plankton. I am unaware of any counterexamples of longterm ecosystem-wide reductions in power, nor have I found cases of protracted reversals.

As is the case for increases in maximum power at the level of lineages, the intensification and spread of ecosystem-wide processes consistent with increasing emergent power are stepwise and continuous because of their dependence on power-enhancing innovations among competitors. Increases in the depth and intensity of bioturbation of marine sediments are concentrated in the early Cambrian, Silurian to Devonian, and late Mesozoic and Cenozoic (Thayer 1983; Tarhan 2018). There are similar but later stepwise increases in the bioturbation of terrestrial soils (Genise et al. 2016). Labandeira (2006) distinguishes four steps in the intensification of herbivory on land. Stepwise increases in the expression of shell defenses and of the capacity of predators to break or enter the shells of marine mollusks occur in the early Cambrian, Silurian to early Carboniferous, Late Triassic to Early Jurassic, Late Cretaceous, and Neogene (Vermeij et al. 1981; Vermeij 1987, 2004; Kowalewski et al. 1998; Harper 2003).

Trends in individual and collective power were briefly, dramatically, but incompletely reversed from time to time by externally imposed disruptions associated with mass extinctions and partial ecosystem collapse. Based on maximum estimated body masses of top animal competitors on land (Smith et al. 2016), and assuming that this biomass correlates with power at more inclusive scales, the reduction in power in the most productive ecosystems at the end-Permian crisis is estimated to be from $2 \times 10^{3} \mathrm{~kg}$ to $30 \mathrm{~kg}$, or three orders of magnitude; and at the endCretaceous crisis to be from $1.5 \times 10^{4} \mathrm{~kg}$ to about $100 \mathrm{~kg}$, or two orders of magnitude. The reversals and subsequent recovery phases comprise at most 15 Myr to 20 Myr of Phanerozoic time, or $2.8 \%$ to $3.7 \%$ of the last 540 Myr. Restoration of stability and well-regulated chemical cycles enabled body mass during postcrisis intervals to rise rapidly, especially in lineages in which there was a premium on fast growth, and therefore high metabolic rate.

Global primary productivity was evidently stimulated by various processes acting at different times. These include, among others, global erosion following glaciations during the Cryogenian and near the end of the Ediacaran (Erwin 2015; Brocks et al. 2017); collisions between volcanic arcs and continents (Macdonald et al. 2019); massive submarine volcanic eruptions, especially during the Mesozoic, which released nutrients for marine organisms and copious carbon dioxide that made photosynthesis on land more efficient (Vermeij 1995; Liu et al. 2018); newly uplifted mountains, especially during the Cambrian and Neogene, which enabled rivers to carry vast amounts of nutrients to the ocean (Potter and Szatmari 2009; Erwin 2015). These physical processes were associated with increasing productivity (Allmon and Martin 2014) and would have facilitated the spread of high-powered life-forms.

By themselves, however, it is doubtful that such stimuli could have initiated ecosystemwide increases in power. If powerful organisms and their supporting ecosystems did not already exist to capture and recycle the newly injected resources, the added nutrients would quickly have been conveyed to geological reservoirs where they would be out of reach for active members of ecosystems. The Cryogenian boost in nutrients (Brocks et al. 2017) coincided with the rise of algae and of suspension-feeding sponges; and the later Mesozoic nutrient stimulus is linked to major Cretaceous innovations in 
the sea and on land (Vermeij 1995, 2011b; Bambach 1999). Likewise, nutrient inputs during the early Paleozoic (Erwin 2015; Servais et al. 2016b), Late Devonian and early Carboniferous (Dahl et al. 2010; Servais et al. 2016a), and Late Triassic to Early Jurassic (Vermeij 2008) enabled powerful entities to capitalize on the newly available resources and to keep those resources in the active biosphere.

It is notable that the stepwise but persistent trend toward greater power at the ecosystem and global scale proceeded despite fluctuations in tectonic activity (Silver and Behn 2008; Macdonald et al. 2019). It was also not affected by purported global-scale cycles in extinction and taxonomic diversity identified by Melott and Bambach (2014). Expansion in an increasingly powerful aerobic biosphere therefore appears to be due to life itself and to be paced by rare innovations in particular lineages under geologic and biological conditions that are conducive to power-intensive modes of life. The human-dominated biosphere falls in line with this long-term directionality. Innovations - almost all of them cultural - have accelerated over time (Vermeij and Leigh 2011), and diversity is expressed not as species number, but as the number of occupations within a single species (Vermeij and Leigh 2011). The underlying positive feedbacks continue to make the biosphere more powerful. The concern remains whether the staggeringly rapid increase in global power during the Anthropocene (Brown et al. 2011; Waters et al. 2016) is sustainable or whether it will lead to unprecedented internally generated collapse.

\section{Conclusions and Open Questions}

The dichotomy between contingency and directionality is a false one. Both claims are valid, but they apply to different scales of inclusion. Contingency rules at the scale of particulars - events, local conditions, and participants - whereas directionality emerges at the larger scale of economic systems. The principal directional trend at this larger scale is an increase in collective power, an expansion of the living world away from thermodynamic equilibrium, driven by the cumulative effects of selective competition for locally scarce resources. The most powerful competitors disproportionately influence the structure and the directions of change in the economies in which they evolve. Histories of life at independent sites will surely differ in detail, but they should exhibit a similar long-term increase in the strength of positive feedbacks and in system-wide power.

From this perspective, historians of life on Earth and of human affairs might look beyond the particulars of time, place, and participants to discern principles governing interactions and the circumstances that enhance and limit them. For paleobiology, this reorientation would involve applying inferences about phylogeny, functional morphology, and physiology to an increased emphasis on the emergent properties of interactions among individuals and among ecological guilds. History is much more than knowing who descended from whom or tracking taxonomic diversity through space and time. Participants are important in history for what they do, how they interact, and what the consequences of their interactions are. To understand history, we need to know how the particulars come together to create emergent relationships, structures, and trends.

Given the critical role that feedbacks play in interactions, a reorientation from simple cause-and-effect chains to networks of intertwined causes and consequences would also benefit historians. Such a shift in approach will enable us to ask how feedbacks begin and end, and when stabilizing negative feedbacks take over from positive ones and vice versa. Isotopic ratios have figured prominently in studies of ecosystem-level and global geochemical cycles and the processes governing them. Such ratios are based on preserved carbon and other elements, but they cannot fully capture parts of cycles that do not involve fossilization. For this reason I suggest that properties, trends, and processes of ecosystems of the past be inferred from the characteristics and observable interactions of organisms as represented by body fossils and traces. Modeling, together with a careful assessment of underlying assumptions, may ultimately make inferences from isotopic data more robust, but this too will require a better understanding of actual organisms and how they work and interact. 
Finally, and most speculatively, the increasing concentration of power over time might characterize all emergent systems and interacting nonidentical particles. Although the underlying mechanisms proposed here apply specifically to metabolizing living things and their interactions, it is an open question whether life is essential for generating directionality. Gravity ensures that larger bodies exert disproportionate influences on their neighborhoods, including smaller particles, suggesting a mechanism for concentrating mass and power at large scales to some point defined by black holes. As in the biosphere, contingency reigns at the scale of movements and positions of individual particles, while interactions among nonidentical particles generate emergent patterns that are more predictable.

\section{Literature Cited}

Albers, S. V., and K. F. Jarrell. 2015. The archaellum: how Archaea swim. Frontiers in Microbiology 6:23.

Allmon, W. D., and R. E. Martin. 2014. Seafood through time revisited: the Phanerozoic increase in marine trophic resources and its macroevolutionary consequences. Paleobiology 40:251-287.

Bambach, R. K. 1993. Seafood through time - changes in biomass, energetics, and productivity in the marine ecosystem. Paleobiology 19:372-397.

Bambach, R. K. 1999. Energetics in the global marine fauna: a connection between terrestrial diversification and change in the marine biosphere. Geobios 32:131-144.

Beatty, J. 2006. Replaying life's tape. Journal of Philosophy 103:336-362.

Blount, Z. B., R. E. Lenski, and J. B. Losos. 2018. Contingency and determinism in evolution: replaying life's tape. Science 362 : eaam5979.

Bonner, J. T. 1952. Morphogenesis: an essay on development. Princeton University Press, Princeton, N.J.

Boyce, C. K., and J.-E. Lee. 2010. An exceptional role for flowering plant physiology in the expansion of tropical rain forests and biodiversity. Proceedings of the Royal Society of London B 277:3437-3443.

Boyce, C. K., and A. B. Leslie. 2012. The paleontological context of angiosperm vegetative evolution. International Journal of Plant Sciences 173:561-568.

Boyce, C. K., T. J. Brodribb, T. S. Field, and M. A. Zweniecki. 2009. Angiosperm leaf vein evolution was physiologically and environmentally transformative. Proceedings of the Royal Society of London B 276:1771-1776.

Boyce, C. K., and M. A. Zwieniecki. 2019. The prospects for constraining productivity through time with the whole-plant physiology of fossils. New Phytologist 223:40-49.

Brocks, J. J., A. J. M. Jarrett, E. Sirantoine, C. Hallmann, Y. Hoshino, and T. Liyanage. 2017. The rise of algae in Cryogenian oceans and the emergence of animals. Nature 548:578-581.

Brodribb, T. J., and S. A. M. McAdam 2011. Passive origins of stomatal control in vascular plants. Science 331:582-585.

Brodribb, T. J., G. J. Jordan, and R. J. Carpenter. 2013. Unified changes in cell size permit coordinated leaf evolution. New Phytologist 199:559-570.
Brown, J. H., H. A. Marquet, and M. L. Taper. 1993. Evolution of body size: consequences of an energetic definition of fitness. American Naturalist 142:573-584.

Brown, J. H., W. H. Burnside, A. D. Davidson, J. P. DeLong, W. C. Dunn, M. J. Hamilton, et al. 2011. Energetic limits to economic growth. BioScience 61:19-26.

Brunet, T., and D. Arendt. 2016. From damage response to action potentials: early evolution of neural and contractile modules in stem eukaryotes. Philosophical Transactions of the Royal Society of London B 371:2015.0043.

Bush, A. M., G. Runt, and R. K. Bambach. 2016. Sex and the shifting biodiversity dynamics of marine animals in deep time. Proceedings of the National Academy of Sciences USA 113:1407314078.

Butterfield, N. J. 2018. Oxygen, animals and aquatic bioturbation: an updated account. Geobiology 16:3-16.

Camillini, N., M. Larsen, and R. N. Glud. 2019. Behavioural pattern of the soft-shell clam Mya arenaria: implications for benthic oxygen and nitrogen dynamics. Marine Ecology Progress Series 622:1034119.

Canfield, D. E., M. T. Rosing, and C. Bjerrum. 2006. Early anaerobic metabolisms. Philosophical Transactions of the Royal Society of London B 361:1819-1836.

Chaisson, E. J. 2001. Cosmic evolution: the rise of complexity in nature. Harvard University Press, Cambridge, Mass.

Conway Morris, S. S. 2003. Life's solution: inevitable humans in a lonely universe. Cambridge University Press, Cambridge.

Corning, P. A. 2014. Evolution "on purpose": how behaviour has shaped the evolutionary process. Biological Journal of the Linnean Society 112:242-260.

Crockford, P. W., J. A. Hayles, H. Bao, N. J. Planavsky, A. Bekker, P. W. Fralick, G. P. Halverson, T. H. Lui, Y. Peng, and B. A. Wing. 2018. Triple oxygen isotope evidence for limited mid-Proterozoic primary productivity. Nature 559:613-616.

Dahl, T. W., E. U. Hammarlund, A. D. Anbar, D. P. G. Bond, B. C. Gill, G. W. Gordon, A. H. Knoll, A. J. Nielsen, N. H. Schovsbo, and D. E. Canfield. 2010. Devonian rise in atmospheric oxygen correlated to the radiations of terrestrial plants and large predatory fish. Proceedings of the National Academy of Sciences USA 107:17911-17915.

DeLong, J. P. 2008. Maximum power principle predicts the outcomes of two-species competition experiments. Oikos 117:13291336 .

DeLong, J. P., J. G. Okie, M. E. Moses, R. M. Sibly, and J. H. Brown. 2010. Shifts in metabolic scaling; production, and efficiency across major evolutionary transitions of life. Proceedings of the National Academy of Sciences USA 107:12941-12945.

Doughty, C. E. 2017. Herbivores increase the global availability of nutrients over millions of years. Nature Ecology and Evolution 1:1820-1827.

Erwin, D. H. 2015. Was the Ediacaran-Cambrian radiation a unique evolutionary event? Paleobiology 41:2-15.

Erwin, D. H., M. Laflamme, S. M. Tweedt, E. A. Sperling, D. P. Sani, and K. J. Peterson. 2011. The Cambrian conundrum: early divergence and later ecological success in the early history of animals. Science 334:1091-1096.

Ferrón, H. 2017. Regional endothermy as a trigger for gigantism in some extinct macropredatory sharks. PLoS ONE 12:e0185185.

Ferrón, H. G., Martinez-Perez, and H. Botella. 2018. The evolution of gigantism in active marine predators. Historical Biology 30:712-716.

Genise, G. F., E. Gedatou, E. S. Bellosi, L. C. Sarzetti, M. V. Sánchez, and J. M. Krause. 2016. The Phanerozoic four revolutions and evolution of paleosol ichnofabrics. Pp. 301-370 in M. G. Mángano and L. A. Buatois, eds. The trace-fossil record of major evolutionary events, Vol. 2. Mesozoic and Cenozoic. Springer Science + Business Media, Dordrecht, Netherlands. 
Gibiasnky, M. L., J. C. Conrad, F. Jin, V. D. Gordon, D. A. Motto, M. A. Mathewson, W. G. Stopka, D. C. Zelasko, J. D. Shrout, and G. C. Wong. 2010. Bacteria use type IV pili to walk upright and detach from surfaces. Science 330:197.

Gould, J. L., and C. G. Gould. 2007. Animal architects: building and the evolution of intelligence. Basic Books, New York.

Gould, S. J. 1985. The paradox of the first tier: an agenda for paleobiology. Paleobiology 11:2-12.

Gould, S. J. 1989. Wonderful life: the Burgess Shale and the nature of history. Norton, New York.

Gould, S. J. 1996. Full house: the spread of excellence from Plato to Darwin. Harmony, New York.

Harper, E. M. 2003. Assessing the importance of drilling predation over the Palaeozoic and Mesozoic. Palaeogeography, Palaeoclimatology, Palaeoecology 201:185-198.

Harshey, R. M., I. Kawagishi, J. Maddock, and L. J. Kenney. 2003. Function, diversity and evolution of signal transduction in prokaryotes. Developmental Cell 4:459-465.

Heim, N. A., M. L. Knope, E. K. Schaal, S. C. Wang, and J. L. Payne. 2015. Cope's rule in the evolution of marine animals. Science 347:867-870.

Heinrich, B. 1993. The hot-blooded insects: strategies and mechanisms of thermoregulation. Harvard University Press, Cambridge, Mass.

Hetherington, A. J., and L. Dolan. 2018. Stepwise and independent origins of roots among land plants. Nature 561:235-238.

Ibarra, D. E., J. K. Caves Rugenstein, A. Bachan, A. Baresch, K. L. Lau, D. L. Thomas, J.-E. Lee, C. K. Boyce, and C. P. Chamberlain. 2019. Modeling the consequences of land plant evolution on silicate weathering. American Journal of Science 319:1-43.

Jékely, G., and D. Arendt. 2006. Evolution of intraflagellar transport from coated vesicles and autogenous origin of the eukaryotic cilium. BioEssays 28:191-198.

Judson, O. P. 2017. The energy expansions of evolution. Nature Ecology and Evolution 1:0148.

Kidder, D. L., and D. R. Erwin. 2001. Secular distribution of biogenic silica through the Phanerozoic: comparison of silicareplaced fossils and bedded cherts at the series level. Journal of Geology 109:509-522.

Kidwell, S. M., and P. J. Brenchley. 1996. Evolution of the fossil record: thickness trends in marine skeletal accumulations and their implications. Pp. 299-336 in D. Jablonski, D. E. Erwin, and J. R. Lipps, eds. Evolutionary paleobiology: in honor of James W. Valentine. University of Chicago Press, Chicago.

Knoll, A. H., and R. K. Bambach. 2000. Directionality in the history of life: diffusion from the left wall or repeated sealing of the right? Paleobiology 26 (Suppl. to No. 4):1-14.

Knoll, A. H., and M. J. Follows. 2016. A bottom-up perspective on ecosystem change in Mesozoic oceans. Proceedings of the Royal Society of London B 283:2016.1755.

Kowalewski, M., A. Dulai, and F. T. Fürsich. 1998. A fossil record full of holes: the Phanerozoic history of drilling predation. Geology 26:1091-1094.

Labandeira, C. C. 2006. The four phases of plant-arthropod associations in deep time. Geologica Acta 4:409-438.

Lane, N. 2015. The vital world: energy, evolution, and the origins of complex life. Norton, New York.

Lane, N., and W. Martin. 2010. The energetics of genome complexity. Nature 467:929-934.

Leigh, E. G., Jr., and G. J. Vermeij. 2002. Does natural selection organize ecosystems for the maintenance of high productivity and diversity? Philosophical Transactions of the Royal Society of London B 357:709-718.

Lenton, T. M., T. W. Dahl, S. J. Daines, B. J. W. Milis, K. Ozaki, M. R. Saltzman, and P. Porada. 2016. Earliest land plants created modern levels of atmospheric oxygen. Proceedings of the National Academy of Sciences USA 113:9704-9709.

Leslie, A. B. 2011a. Predation and protection in the macroevolutionary history of conifer cones. Proceedings of the Royal Society of London B 278:3003-3008.

Leslie, A. B. 2011b. Shifting functional roles and the evolution of conifer pollen-producing and seed-producing cones. Paleobiology 37:587-602.

Levis, N. A., and D. W. Pfennig. 2019. Plasticity-led evolution: evaluating the key prediction of frequency-dependent adaptation. Proceedings of the Royal Society of London B 286:2018.2754.

Liu, K. K., Q. Feng, J. Shen, M. Khan, and N. J. Planavsky. 2018. Increased productivity as a primary driver of marine anoxia in the Lower Cambrian. Palaeogeography, Palaeoclimatology, Palaeoecology 491:1-9.

Losos, J. B. 2017. Impossible destinies: fate, chance, and the future of evolution. Riverhead, New York.

Lovegrove, B. G. 2017. A phenology of the evolution of endothermy in birds and mammals. Biological Reviews 92:1213-1240.

Macdonald, F. A., N. L. Swanson-Hysell, Y. Park, L. Lisieck, and O. Jagoutz. 2019. Arc-continental collisions set Earth's climate state. Science 364:181-184.

Martens, E. A., N. Wadhwa, N. T. Jacobsen, C. Lindemann, H. Andersen, and A. Visser. 2015. Sense structures sensory hierarchy in ocean life. Proceedings of the Royal Society of London B 282:2015.1346.

McAdam, S. A., and T. J. Brodribb. 2012. Stomatal innovation and the rise of seed plants. Ecology Letters 15:1-8.

McShea, D. W. 1998. Possible large/scale trends in organismal evolution: eight "live hypotheses." Annual Review of Ecology and Systematics 29:293-318.

McShea, D. W. 1996. Metazoan complexity and evolution: is there a trend? Evolution 50:477-492.

McShea, D. W. 2016a. Freedom and purpose in biology. Studies in History and Philosophy of Science Part C: Studies in History and Philosophy of Biology and Biomedical Sciences 58:64-72.

McShea, D. W. 2016b. Three trends in the history of life: an evolutionary syndrome. Evolutionary Biology 43:531-541.

McShea, D. W., and R. N. Brandon. 2010. Biology's first law: the tendency for diversity and complexity to increase in evolutionary systems. University of Chicago Press, Chicago.

Melott, A. L., and R. K. Bambach. 2014. Analysis of periodicity of extinction using the 2012 Geological Timescale. Paleobiology 40:177-196.

Mulcahy, D. L. 1979. The rise of the angiosperms: a genecological factor. Science 206:20-23.

Ord, T. J., and T. C. Summers. 2015. Repeated evolution and the impact of evolutionary history on adaptation. BMC Evolutionary Biology 15:137.

Oudman, T., and T. Piersma. 2018. De Ontsnapping van de Natuur: Een Nieuwe Kijk op Kennis. Athenaeum Polak and Van Kennep, Amsterdam.

Payne, J. L., A. G. Boyer, J. H. Brown, S. Finnegan, M. Kowalewski, R. A. Krause , Jr., S. K. Lyons, et al. 2009. Two-phase increase in the maximum size of life over 3.5 billion years reflects biological innovation and environmental opportunity. Proceedings of the National Academy of Sciences USA 106:24027.

Payne, J. L., C. R. McClain, A. G. Boyer, J. H. Brown, S. Finnegan, M. Kowalewski, R. A. Krause , Jr., et al. 2011. The evolutionary consequences of oxygenic photosynthesis: a body size perspective. Photosynthesis Research 107:37-57.

Peters, S. E., and R. R. Gaines. 2012. Formation of the "Great Unconformity" as a trigger for the Cambrian explosion. Nature 484:363366. 
Polin, M., I. Tuval, K. Drescher, J. P. Gollub, and R. E. Goldstein. 2009. Chlamydomonas swims with two "gears" in a eukaryotic version of run-and-tumble locomotion. Science 325:487-490.

Por, F. D. 1994. Animal achievement: a unifying theory of zoology. Balaban Publishers, Rehovot, Israel.

Potter, P. E., and P. Szatmari. 2009. Global Miocene tectonics and the modern world. Earth-Science Reviews 96:279-295.

Powell, R. 2012. Convergent evolution and the limits of natural selection. European Journal of the Philosophy of Science 2:355373.

Powell, R., and C. Mariscal. 2015. Convergent evolution as natural experiment: the tape of life reconsidered. Interface Focus 5:2015.0040.

Prum, R. O. 2017. The evolution of beauty: how Darwin's forgotten theory of mate choice shapes the animal world - and us. Doubleday, New York.

Ridgwell, A., and R. E. Zeebe. 2005. The role of the global carbonate cycle in the regulation and evolution of the Earth system. Earth and Planetary Science Letters 234:299-315.

Robinson, J. M. 1990. The burial of organic carbon as affected by the evolution of land plants. Historical Biology 3:189-201.

Schinazi, R. B. 2019. Can evolution paths be explained by chance alone? Journal of Theoretical Biology 467:63-65.

Servais, T., R. E. Martin, and A. Nützel. 2016a. The impact of the "terrestrialisation process" in the Late Palaeozoic: $\mathrm{pCO}_{2}, \mathrm{pO}_{2}$, and the "phytoplankton blackout." Review of Palaeobotany and Palynology 224:26-37.

Servais, T., V. Perrier, T. Danelian, C. Klug, R. Martin, A. Munnecke, H. Nowak, et al. 2016b. The onset of the "Ordovician plankton revolution" in the Late Cambrian. Palaeogeography, Palaeoclimatology, Palaeoecology 458:12-28.

Seymour, J. R., and J.-B. Raina. 2018. Swimming in the sea: chemotaxis by marine bacteria. Microbiology Australis 39:12-16.

Shubin, N., C. Tabin, and S. Carroll. 2009. Deep homology and the origins of evolutionary novelty. Nature 457:818-823.

Silver, P. G., and M. D. Behn. 2008. Intermittent plate tectonics? Science 319:85-88.

Simpson, G. G. 1964. The nonprevalence of humanoids. Science 143:669-675.

Smith, F. A., J. L. Payne, N. A. Heim, M. A. Balk, S. Finnegan, M. Kowalewski, T. K. Lyons, et al. 2016. Body size evolution across the Geozoic. Annual Review of Earth and Planetary Sciences 44:523-553.

Steneck, R. S. 1983. Escalating herbivory and resulting adaptive trends in calcareous algal crusts. Paleobiology 9:44-61.

Stocker, R., and L. M. Durham. 2009. Tumbling and stealth. Science 325:400-402.

Tarhan, L. G. 2018. The Early Paleozoic development of bioturbation-evolutionary and geobiological consequences. EarthScience Reviews 178:177-207.

Thayer, C. W. 1983. Sediment-mediated biological disturbance and the evolution of marine benthos. Pp. 479-625 in M. J. S. Tevesz and P. L. McCall, eds. Biotic interactions in recent and fossil benthic communities. Plenum, New York.

Turner, J. S. 2007. The tinkerer's accomplice: how design emerges from life itself. Harvard University Press, Cambridge, Mass.

Van Leeuwen, A., A. M. De Roos, and L. Persson. 2008. How cod shapes its world. Journal of Sea Research 60:89-104.

Van Valen, L. 1975. Group selection, sex, and fossils. Evolution 29:87-93.

Van Valen, L. 1976. Energy and evolution. Evolutionary Theory 1:1-25.

Van Valkenburgh, B., X. Wang, and J. Damuth. 2004. Cope's rule, hypercarnivory, and extinction in North American canids. Science 306:101-104.
Vermeij, G. J. 1982. Unsuccessful predation and evolution. American Naturalist 120:701-720.

Vermeij, G. J. 1987. Evolution and escalation: an ecological history of life. Princeton University Press, Princeton, N.J.

Vermeij, G. J. 1995. Economics, volcanoes, and Phanerozoic revolutions. Paleobiology 21:125-152.

Vermeij, G. J. 2002. Characters in context: molluscan shells and the forces that mold them. Paleobiology 28:41-54.

Vermeij, G. J. 2004. Nature: an economic history. Princeton University Press, Princeton, N.J.

Vermeij, G. J. 2006. Historical contingency and the purported uniqueness of evolutionary innovations. Proceedings of the National Academy of Sciences USA 103:1804-1809.

Vermeij, G. J. 2008. Escalation and its role in Jurassic biotic history. Palaeogeography, Palaeoclimatology, Palaeoecology 263:3-8.

Vermeij, G. J. 2010. The evolutionary world: how adaptation explains everything from seashells to civilization. Thomas Dunne/St. Martin's, New York.

Vermeij, G. J. 2011a. The energetics of modernization: the last one hundred million years of biotic history. Paleontological Research 15:55-61.

Vermeij, G. J. 2011b. Shifting sources of productivity in the coastal marine tropics during the Cenozoic era. Proceedings of the Royal Society of London B 278:2362-2368.

Vermeij, G. J. 2013a. On escalation. Annual Review of Earth and Planetary Sciences 41:1-19.

Vermeij, G. J. 2013b. The evolution of molluscan photosymbioses: a critical appraisal. Biological Journal of the Linnean Society 109:497-511

Vermeij, G. J. 2015. Forbidden phenotypes and the limits of evolution. Interface Focus 5:2015.0028.

Vermeij, G. J. 2016. Gigantism and its implications for the history of life. PLoS ONE 11:e0146092.

Vermeij, G. J. 2017. How the land became the locus of major evolutionary innovations. Current Biology 27:3178-3182.

Vermeij, G. J. 2019. The efficiency paradox: how wasteful competitors forge thrifty ecosystems. Proceedings of the National Academy of Sciences USA 116:17619-17623.

Vermeij, G. J., and E. G. Leigh , Jr. 2011. Natural and human economies compared. Ecosphere 2:39.

Vermeij, G. J., and D. R. Lindberg. 2000. Delayed herbivory and the assembly of marine benthic ecosystems. Paleobiology 26:419-430.

Vermeij, G. J., D. E. Schindel, and E. Zipser. 1981. Predation through geological time: evidence from gastropod shell repair. Science 214:1024-1026.

Wagner, G. P. 2014. Homology, genes, and evolutionary innovation. Princeton University Press, Princeton, N.J.

Wake, D. B, M. H. Wake, and C. D. Specht. 2011. Homoplasy: from detecting pattern to determining process and mechanism of evolution. Science 33:1032-1035.

Ward, L. M., B. Rasmussen, and W. W. Fischer. 2019. Primary productivity was limited by electron donors prior to the advent of oxygenic photosynthesis. Journal of Geophysical Research: Biogeosciences 124:211-226.

Waters, C. N., J. Zalasiewicz, C. Summerhayes, A. D. Barnosky, C. Poirier, A. Gałuszka, A. Cearreta, et al. 2016. The Anthropocene is functionally and stratigraphically distinct from the Holocene. Science 351:AAAD2622.

Whalen, C. D., and D. E. G. Briggs. 2017. The Palaeozoic colonization of the water column and the rise of global nekton. Proceedings of the Royal Society of London B 285:2018.0883.

Williams, J. J., Y. P. Papastamatiou, J. E. Caselle, D. Bradley, and D. M. P. Jacoby. 2018. Mobile marine predators: an understudied source of nutrients to coastal reefs in an unfished atoll. Proceedings of the Royal Society of London B 285:2017.2456. 